\title{
PENGARUH KETINGGIAN LUBANG UDARA PADA TUNGKU PEMBAKARAN BIOMASSA TERHADAP UNJUK KERJANYA
}

\author{
Arif Mulyanto*, Mirmanto, Muhammad Athar \\ Teknik Mesin, Fakultas Teknik, Universitas Mataram, Jln. Majapahit No.62 Mataram Nusa \\ Tenggara Barat Kode Pos: 83125, Telp. (0370) 636087; 636126; ext 128 Fax (0370) 636087 \\ *Email: gamulkky@yahoo.co.id
}

\begin{abstract}
Alternative energies, e.g. biomassa, can be utilized using combustion processes in a stove. Nevertheless, traditional stoves that are available in the market or have been used by the community for years are not effective and efficient. One thing that may affect their efficiency and effectiveness is a distance between the combustion chamber and air hole. Therefore, this research investigates experimentally the effect of the distance. The tested stoves had identical combustion room and air hole diameters, but the distance between the combustion chamber and air hole was varied $10 \mathrm{~cm}, 20 \mathrm{~cm}, 30 \mathrm{~cm}, 40 \mathrm{~cm}$. The combustion chamber diameter was $13 \mathrm{~cm}$ and the top diameter of the stove was $19 \mathrm{~cm}$. The fuel employed was coconut shell with various size of 2-4 cm and 5-10 cm. One traditional stove was also tested as a comparison. The test were conducted by heating the water in a $18 \mathrm{~cm}$ diameter pan from the ambient temperature to the boiling temperature $\left(100^{\circ} \mathrm{C}\right)$. Investigated parameters showing the stove performance were boiling time, FCR, heat input, heat output, heat losses and efficiency. The results show that the fastest boiling time $(472 \mathrm{~s})$ and the highest $F C R(0,9407 \mathrm{Kg} / \mathrm{h})$ were resulted in the stove with the air hole distance of $40 \mathrm{~cm}$ and coconut shell size of $5-10 \mathrm{~cm}$. In this stove, the highest heat input, heat output, heat losses occurred too. On the other hand, the highest efficiency $(15,62 \%)$ was achieved in the stove with the air hole distance of $10 \mathrm{~cm}$.
\end{abstract}

Keywords: stove, air hole distance, fuel size, FCR, boiling time, efficiency

\section{PENDAHULUAN}

Tingkat pemakaian bahan bakar fosil didunia semakin meningkat seiring meningkatnya populasi manusia dan meningkatnya laju industrialisasi, apabila konsumsi bahan bakar ini tidak dibatasi maka krisis bahan bakar minyak (BBM) tinggal menunggu waktu. Pengurangan konsumsi bahan bakar fosil sesuai dengan blue print pengelolaan energi nasional 2005-2025, kebijakan indonesia memilki sasaran salah satunya adalah meningkatkan energi terbarukan (penggunaan energi bomassa) menjadi $15 \%$ dari total pemakaian sumber energi (Risenggara, 2008 dalam Utami 2008).

Salah satu bentuk energi alternatif yang jumlahnya melimpah dengan kandungan energi yang besar adalah biomasssa. Hampir 2 milyar penduduk negara berkembang termasuk indonesia terutama yang bermukim dipedesaan sudah sejak lama mengandalkan bahan bakar biomassa dan teknologi tradisional untuk kepentingan memasak dan pemanasan. Biomassa yang sering digunakan antara lain kayu bakar, batok kelapa, serbuk gergaji, ampas tebu, sekam padi dll (Kumaradasa et al, 1999 dalam suhandi dkk, 2013).

Untuk mengkonversi energi yang terkandung dalam biomassa digunakan tungku pembakaran lansung, kemudian panas yang dihasilkan digunakan untuk keperluan memasak. Desain tungku yang digunakan oleh masyarakat masih sangat sederhana sehingga efisiensi pembakaran masih sangat rendah (Robith, 2004 dalam Budianto dkk, 2014). Desain tungku yang baik adalah menciptakan pembakaran yang sempurna, ruang pembakaran pada tungku harus memperhatikan pola aliran yang terbentuk ketika fluida (udara, gas, dan hasil pembakaran) melalui unggun kayu bakar. Selain itu bentuk geometri ruang bakar, lubang pemasukan aliran udara juga sangat mempengaruhi pola aliran yang dihasilkan.

Tujuan dari penelitian ini adalah untuk Mengetahui pengaruh variasi ketinggian lubang udara dan variasi ukuran bahan bakar terhadap karakteristik dari tungku pembakaran biomassa

Manfaat yang diharapkan dari penelitian ini adalah dapat memberikan informasi tentang penggunaan bahan bakar alternatif serta perbaikan bentuk desain dari tungku pembakaran tradisional.

Hasil penelitian Maulana (2009) menunjukkan bahwa efisiensi paling baik dihasilkan dengan perlakuan diberi satu lubang pemasukan udara, nyala api yang efektif dipengaruhi oleh aliran udara pada tungku sekam yang ber sumber dari udara 
yang terperangkap pada badan kompor. Celah udara yang dibuka luas pada proses pembakaran dapat mempercepat pross pembakaran dan efisiensi waktu pendidihan air dapat optimal, karena dengan celah yang terbuka luas, udara dan oksigen masuk dan bereaksi dengan bara api sehingga mempercepat laju pembakaran (Widiarto, 2012).

Dalam penelitian yang dilakukan oleh Barlin dan Nainggolan (2012) tentang studi performa tungku pembakaran biomassa berbahan bakar limbah sekam padi. Efisiensi termal tungku pembakaran pada masingmasing laju aliran udara primer tersebut adalah 12,364 \%, 11,402\%, 11,402\%, $11,402 \%, 6,123 \%, 5,643 \%, 4,204 \%$ atau berkisar antara 4,204 \% sampai 12,364 \%. Dari hasil penelitian ini dapat disimpulkan bahwa semakin tinggi laju aliran udara primer, maka efisiensi termal akan semakin menurun. Waktu operasi tungku pembakaran tertinggi mencapai 17 menit 54 detik pada kecepatan aliran udara primer 1300 fpm (6,604 m/s).

Penelitian vidian (2012) menunjukkan bahwa membesarnya laju alir udara pada tungku menyebabkan suhu dalam reaktor meningkat. Hal ini disebabkan karena pada laju alir volume udara yang tinggi, maka penetrasi udara ke unggun tempurung lebih besar jika dibandingkan laju alir volume udara yang rendah. Bertambahnya suplai udara maka jumlah oksigen yang dipergunakan untuk pembakaran pada daerah oksidasi juga semakin meningkat. Semakin besar laju alir udara, maka suhu api yang dihasilkan semakin meningkat, sehingga mengakibatkan jumlah gas mampu bakar akan meningkat. Meningkatnya jumlah gas mampu bakar tentu akan meningkatkan jumlah panas yang dilepaskan pada saat pembakaran gas.

Biomassa adalah bahan organik yang dihasilkan melalui proses fotosintetik, baik berupa produk maupun buangan. Contoh biomassa antara lain adalah tanaman, pepohonan, rumput, ubi, limbah pertanian, limbah hutan, tinja dan kotoran ternak. Selain digunakan untuk tujuan primer serat, bahan pangan, pakan ternak, miyak nabati, bahan bangunan dan sebagainya, biomassa juga digunakan sebagai sumber energi (bahan bakar)

Tempurung kelapa merupakan bagian dari buah kelapa yang fungsinya secara biologis adalah pelindung inti buah dan terletak di bagian sebelah dalam sabut dengan ketebalan berkisar antara 2-6 mm.
Tempurung kelapa dikategorikan sebagai kayu keras tetapi mempunyai kadar lignin yang lebih tinggi dan kadar selulosa lebih rendah dengan kadar air sekitar 6-9 \% (Pranata, 2007).

Pemanfaatan tempurung kelapa dapat dilakukan secara langsung sebagai bahan bakar dengan mengkonversi melalui pembakaran sehingga menghasilkan panas. Penggunaan biomassa tempurung kelapa sebagai bahan bakar perlu disertai dengan pengadaan tungku yang harus disesuaikan dengan kebutuhan masyarakat.

Tungku merupakan alat yang digunakan untuk mengkonversi energi potensial biomassa menjadi energi panas. Untuk memperoleh efisiensi pembakaran yang baik dari sebuah tungku, desain teknis tungku harus diperhatikan. Tungku merupakan salah satu komponen dalam proses pengolahan makanan yang dapat meningkatkan kesejahteraan masyarakat, baik dalam skala institusional, industri kecil maupun rumah tangga (Arisanti, 2001 dalam Mulyono 2009). Tungku masak di Indonesia dibuat dari berbagai jenis material seperti: tanah liat, batu cadas, batu bata-semen serta tungku cetak dengan sistem cor.

\section{METODE PENELITIAN}

Dalam penelitian ini dilakukan di workshop fakultas teknik, Universitas mataram dengan menggunakan tungku yang terdiri dari ruang bakar berdiameter $13 \mathrm{~cm}$, diameter bagian atas tungku $19 \mathrm{~cm}$, tinggi ruang bakar $15 \mathrm{~cm}$, diameter lubang udara 5 $\mathrm{cm}$ dengan variasi ketinggian jarak lubang udara dan ruang bakar yaitu $10 \mathrm{~cm}, 20 \mathrm{~cm}, 30$ $\mathrm{cm}$, dan $40 \mathrm{~cm}$ (gambar 1). Alat yang digunakan meliputi tungku biomassa, panci berdiameter $18 \mathrm{~cm}$, termometer air raksa, termometer digital merk krisbow tipe $\mathrm{K}$, timbangan digital merk CHAMMRY kapasitas $5 \mathrm{Kg}$ dengan ketelitian 1 gram, stopwatch, anemometer merk krisbow tipe a15 dengan ketelitian $0,01 \mathrm{~m} / \mathrm{s}$, dan korek api. Bahan penelitian adalah biomassa tempurung kelapa dengan variasi panjang 2-4 cm, dan $5-10 \mathrm{~cm}$, air, dan minyak tanah.

Pembuatan tungku dilakukan di desa Penujak Kecamatan Praya Barat, Kabupaten Lombok Tengah. Adapun prosedur penelitianya adalah

a. Tungku biomassa dalam kondisi siap digunakan untuk pengujian performa tungku. 

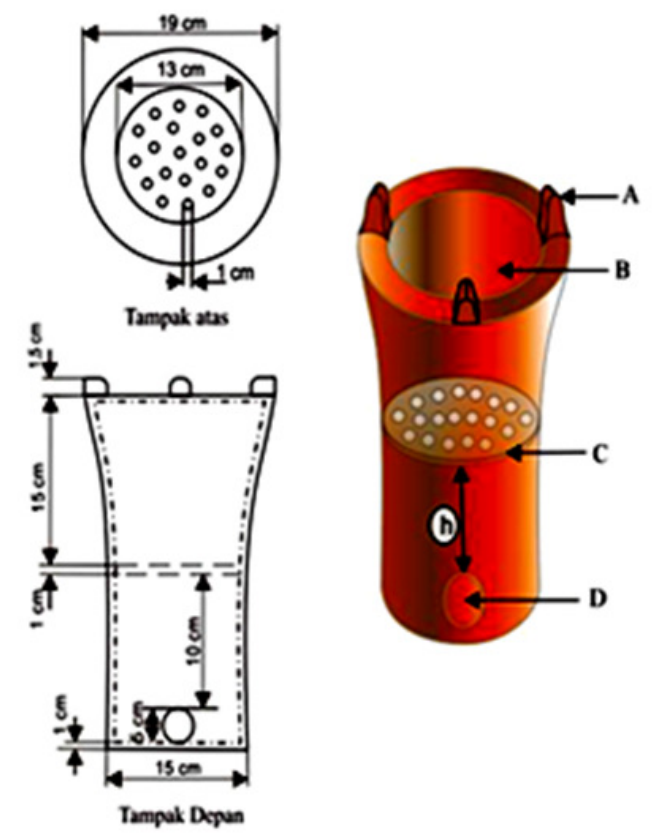

\section{Keterangan :}

$A=$ Tempat dudukan panci

$\mathrm{B}=$ Ruang pembakaran

$\mathrm{C}=$ Kisi-kisi sebagai tempat bahan bakar

$\mathrm{D}=$ Lubang pemasukan udara

$\mathbf{h}=$ Ketinggian jarak lubang udara yang divariasikan

\section{Gambar 1. Tungku pembakaran biomassa}

b. Bahan bakar biomassa yang akan digunakan tersedia dalam jumlah yang cukup untuk memenuhi proses pembakaran selama proses pengujian tungku.

c. Bahan bakar biomassa yang digunakan dalam kondisi kering.

d. Alat uji seperti timbangan, stopwatch, thermometer. anemometer sudah dalam kondisi siap digunakan.

e. Timbang berat biomassa yang diisikan kedalam ruang bakar.

f. Siapkan air (1 Liter $=0,9964 \mathrm{Kg}$ ) yang akan dididihkan pada tungku dan sebelumnya temperatur awal air diukur dan timbang berat air tersebut.

g. Biomassa dalam ruang bakar dibakar menggunakan minyak tanah (10 gr $=0,01$ $\mathrm{Kg}$ ) sebagai pemicu.

h. Panci yang berisi air diletakkan diatas ruang bakar dan catat waktu ketika panci diletakkan diatas ruang bakar.

i. Tunggu air sampai mendidih dan catat waktu yang dibutuhkan sampai air mendidih. Catat juga waktu dalam selang waktu satu menit sampai titik didih dicapai.

j. Dengan cara yang sama (e sampai i) utuk pengujian ketinggian lubang udara $20 \mathrm{~cm}$, $30 \mathrm{~cm}$, dan $40 \mathrm{~cm}$.

\section{Parameter pengujian}

Water Boiling Test (WBT) adalah metode pengujian yang digunakan untuk mengetahui kinerja suatu tungku dalam skala laboratorium, dimana kondisi iklim, bahan bakar (kelembaban, spesies, bentuk), jenis alat masak, pemasak termasuk cara mengoperasikan tungku dipertahankan sama di sepanjang pengujian.

a. Boiling Time adalah waktu yang dibutuhkan untuk memanaskan air pada panci atau ketel, yaitu dihitung mulai dari meletakkan panci pada burner sampai air mendidih pada suhu $100{ }^{\circ} \mathrm{C}$.

b. Fuel Comsumtion Rate (FCR) adalah perbandingan antara jumlah bahan bakar yang terpakai dengan waktu yang dibutuhkan untuk memanaskan air.

$$
\begin{aligned}
& F C R=\frac{m_{b t}}{t} \\
& m_{b t}=m_{a}-m_{a k}
\end{aligned}
$$

Persamaan (1) dan (2) diperoleh dari Barlin dan Nainggolan (2012). Dengan FCR adalah fuel Comsumption Rate, (kg/jam), $\mathrm{m}_{\mathrm{bt}}$ sebagai massa bahan bakar terpakai $(\mathrm{Kg}), \mathrm{m}_{\mathrm{a}}$ adalah massa bahan bakar awal $(\mathrm{Kg}), \mathrm{m}_{\mathrm{ak}}$ merupakan massa bahan bakar akhir $(\mathrm{Kg})$, t adalah waktu untuk mendidihkan air (jam). 
c. Daya bersih $\left(\mathrm{P}_{\text {out }}\right)$ adalah perbandingan antara energi yang digunakan untuk memanaskan air dengan lama waktu yang dibutuhkan untuk mencapai titik didih.

$$
P_{\text {out }}=\frac{M_{w} c_{p}\left(T_{f}-T_{i}\right)}{t}
$$

Persamaan (3) diambil dari Anonim1 (2007). Dengan $P_{\text {out }}$ adalah daya bersih $(\mathrm{kW}), \mathrm{M}_{\mathrm{w}}$ menyatakan massa air, liter (1 Liter $=0,9964$ $\mathrm{Kg}) . \mathrm{C}_{\mathrm{p}}$ adalah kalor jenis air, 4,1866 $\mathrm{kJ} / \mathrm{Kg}^{0} \mathrm{C}, \mathrm{T}_{i}$ adalah temperatur air awal $\left({ }^{\circ} \mathrm{C}\right)$, $\mathrm{T}_{\mathrm{f}}$ menyatakan temperatur air akhir $\left({ }^{0} \mathrm{C}\right)$.

d. Daya Pembakaran $\left(P_{\text {in }}\right)$ adalah energi panas yang terkandung didalam bahan bakar dibagi dengan waktu yang digunakan pada proses pebakaran.

$$
P_{i n}=\frac{m_{b t} L H V}{t}
$$

Dengan $P_{\text {in }}$ adalah daya bersih untuk menaikkan suhu air (kW), LHV merupakan nilai kalor terendah bahan bakar $(\mathrm{kJ} / \mathrm{Kg})$.

e. Daya yang hilang $\left(\mathrm{P}_{\text {losses }}\right)$ adalah kehilangan daya yang dihasilkan dari tungku pembakaran biomassa.

$$
P_{\text {loss }}=P_{\text {in }}-P_{\text {out }}
$$

pembakaran $(\mathrm{kW}), \mathrm{P}_{\text {out }}$ adalah daya yang digunakan untuk menaikkan suhu air $(\mathrm{kW})$.
f. Efisiensi
Tungku
(n) adalah

perbandingan antara daya bersih yang digunakan untuk memanaskan air dengan daya pebakaran bahan bakar.

$\eta=\frac{P_{\text {out }}}{P_{\text {in }}} x 100 \%$

\section{HASIL DAN PEMBAHASAN \\ Boiling Time dan Fuel Consumtion Rate (FCR)}

Boiling time adalah waktu yang dibutuhkan untuk memanaskan air pada panci/ketel, yaitu dihitung mulai meletakkan panci sampai air mencapai suhu $100{ }^{\circ} \mathrm{C}$.

Fuel consumption rate (FCR) adalah perbandingan jumlah konsumsi bahan bakar yang digunakan dalam satu kali pembakaran dengan waktu yang dibutuhkan untuk menghabiskan bahan bakar tersebut.

Dapat terlihat dari gambar 2 bahwa pemanasan air menggunakan tungku dengan ketinggian lubang udara $10 \mathrm{~cm}, 20 \mathrm{~cm}, 30 \mathrm{~cm}$, $40 \mathrm{~cm}$, dan tungku tradisional dengan bahan bakar ukuran panjang 2-4 cm memerlukan waktu rata-rata berturut-turut adalah 706 detik, 650 detik, 592 detik, 536 detik dan 938 detik, ini berbeda dengan boiling time pada tungku dengan ukuran bahan bakar ukuran panjang $5-10 \mathrm{~cm}$ yang memiliki rata-rata lebih cepat pada ketinggian lubang udara $10 \mathrm{~cm}$, $20 \mathrm{~cm}, 30 \mathrm{~cm}, 40 \mathrm{~cm}$ dan tungku tradisional yaitu 620 detik, 570 detik, 516 detik, 472

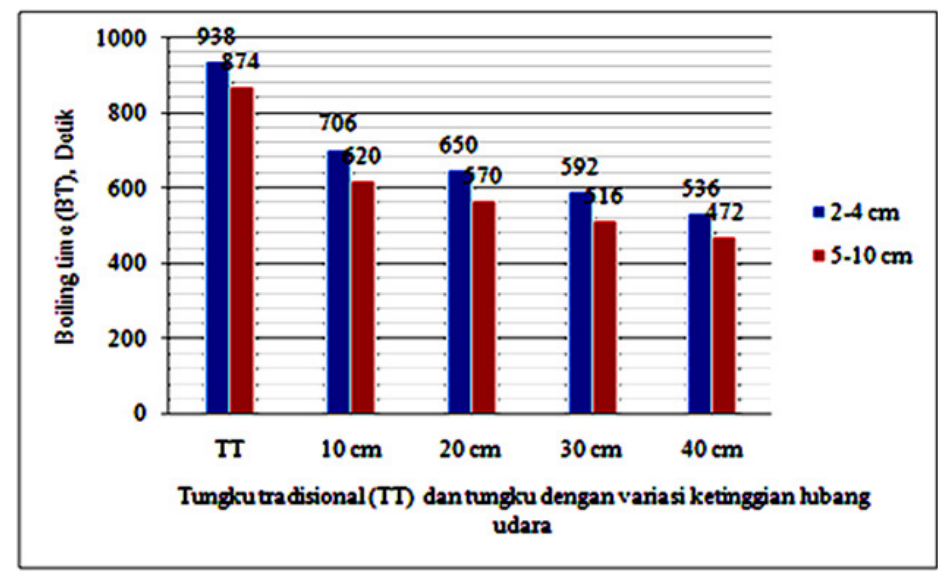

Gambar 2. Hubungan boiling time terhadap variasi lubang udara dengan ukuran panjang bahan bakar $2-4 \mathrm{~cm}$ dan $5-10 \mathrm{~cm}$

Dengan $\mathrm{P}_{\text {loss }}$ menyatakan kehilangan daya detik dan tungku tradisional 874 detik. pada tungku $(\mathrm{kW}), \quad P_{\text {in }}$ adalah daya 
Semakin tinggi jarak lubang udara pada tungku maka boiling time akan semakin cepat karena suplay udara yang dapat kontak dengan bahan bakar semakin baik sehingga suhu panas yang dihasilkan baik dan waktu pemanasan menjadi lebih cepat, proses pembakaran yang lebih baik menghasilkan laju pembakaran yang lebih besar, yang berarti jumlah energi pembakaran meningkat sehingga suhu pembakaran meningkat. udara dengan ukuran bahan bakar 2-4 cm sebesar 0,6067 Kg/Jam pada tungku dengan ketinggian lubang udara $40 \mathrm{~cm}$, konsumsi bahan bakar terendah sebesar 0,3637 $\mathrm{Kg} / \mathrm{Jam}$ pada tungku dengan ketinggian lubang udara $10 \mathrm{~cm}$. Sementara pada ketinggian lubang udara pada tungku dengan ukuran bahan bakar 5-10 cm, nilai konsumsi bahan bakar terbesar pada tungku dengan ketinggian lubang udara $40 \mathrm{~cm}$ yaitu 0,9407

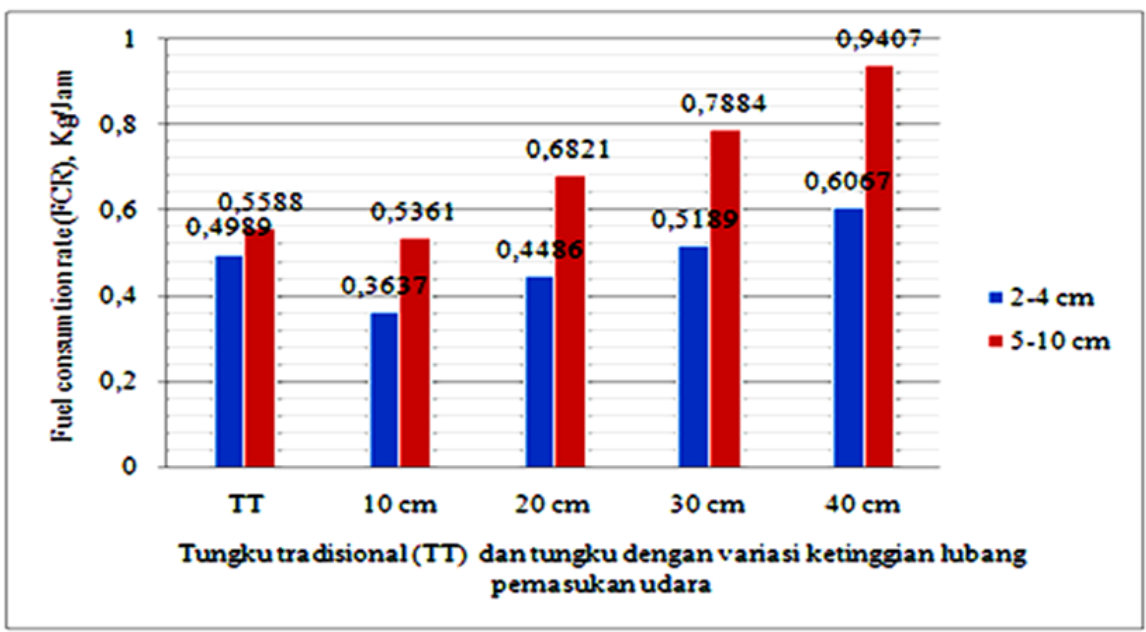

Gambar 3. Hubungan FCR terhadap variasi lubang udara dengan ukuran panjang bahan bakar 2-4 $\mathrm{cm}$ dan $5-10 \mathrm{~cm}$

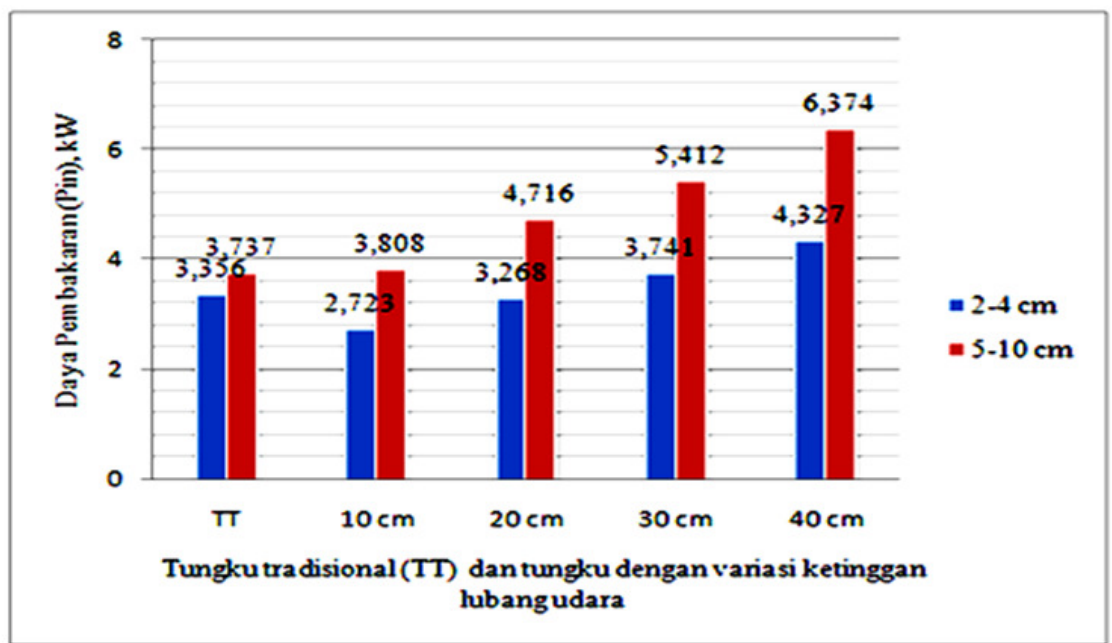

Gambar 4. Hubungan $P_{\text {in }}$ terhadap variasi lubang udara dengan ukuran panjang bahan bakar 2-4 cm dan $5-10 \mathrm{~cm}$

Dari gambar 3 dapat dilihat pengaruh variasi ketinggian lubang udara dan ukuran bahan bakar dengan nilai fuel consumtion rate (FCR), dimana variasi ketinggian lubang
$\mathrm{Kg} / \mathrm{jam}$, dan yang terendah pada ketinggian lubang udara $10 \mathrm{~cm}$ sebesar $0,5361 \mathrm{Kg} / \mathrm{Jam}$. Terlihat bahwa terjadi kenaikan laju konsumsi bahan bakar pada setiap ketinggian lubang 
udara. Semakin tinggi jarak lubang udara, pembakaran menjadi lebih cepat, akibtanya

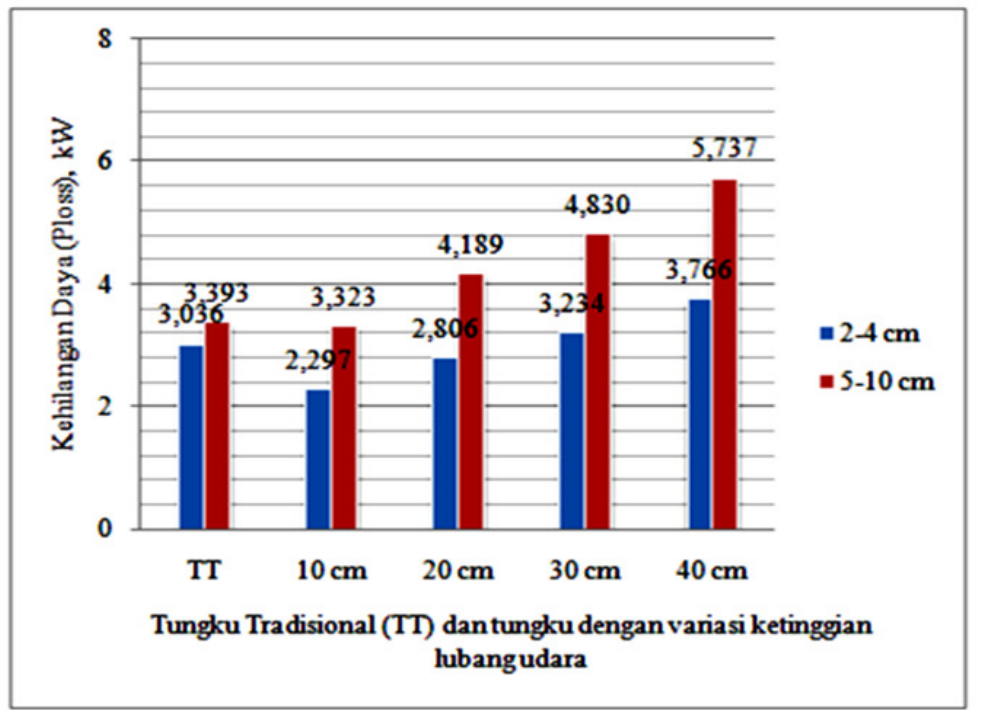

Gambar 5. Hubungan $\mathrm{P}_{\text {loss }}$ terhadap variasi lubang udara dengan ukuran panjang bahan bakar $2-4 \mathrm{~cm}$ dan $5-10 \mathrm{~cm}$

maka laju konsumsi bahan bakar juga akan semakin naik.

Kenaikan laju konsumsi bahan bakar pada setiap ketinggian lubang udara bahan bakar juga akan cepat terbakar. Jika bahan bakar cepat terbakar, maka bahan bakar akan semakin cepat habis.

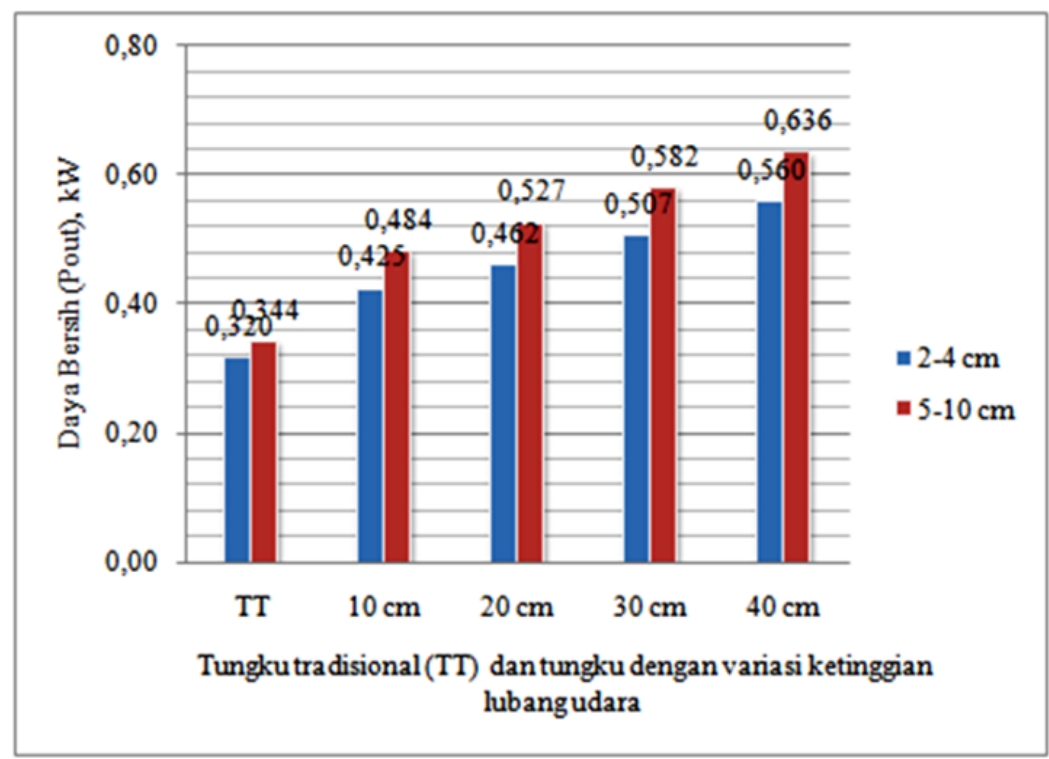

Gambar 6. Hubungan $\mathrm{P}_{\text {out }}$ terhadap variasi lubang udara dengan ukuran panjang bahan bakar $2-4 \mathrm{~cm}$ dan $5-10 \mathrm{~cm}$

disebabkan karena semakin tingginya laju aliran udara. Hal tersebut diakibatkan karena semakin tinggi laju aliran udara, ini berarti bahwa udara yang masuk ke dalam ruang bakar semakin banyak, maka proses
Daya Pembakaran $\left(P_{\text {in }}\right)$, Daya Bersih $\left(P_{\text {out }}\right)$, Kehilangan daya $\left(\boldsymbol{P}_{\text {loss }}\right)$

Dari gambar 4 terlihat bahwa Daya pembakaran dipengaruhi oleh ketinggian jarak lubang udara pada tungku dan ukuran bahan 
bakar. Semakin tinggi jarak lubang udara maka power input yang dihasilkan semakin besar. Pada bahan bakar dengan ukuran 2-4 $\mathrm{cm}$, nilai power input untuk ketinggian lubang udara $10 \mathrm{~cm}, 20 \mathrm{~cm}, 30 \mathrm{~cm}$, dan $40 \mathrm{~cm}$, berturut-turut adalah 2,7226 kW, 3,2678 kW, $3,7409 \mathrm{~kW}$ dan 4,3266 kW. Sedangkan pada ukuran bahan bakar 5-10 cm, nilai power input dari tungku dengan ketinggian jarak lubang pemasukan udara $10 \mathrm{~cm}, 20 \mathrm{~cm}, 30$ $\mathrm{cm}$ dan $40 \mathrm{~cm}$ berturut-turut adalah 3,8078 kW, 4,7160 kW, 5,4120 kW dan 6,3738 kW. Sementara pada tungku tradisional dengn ukuran bahan bakar 2-4 cm dan 5-10 cm menghasilkan rata-rata $3,3558 \mathrm{~kW}$ dan 3,7369 kW. Peningkatan daya pembakaran ini disebabkan karena semakin banyaknya bahan bakar yang terbakar yang mengakibatkan semakin banyaknya daya yang dilepaskan oleh bahan bakar.

Berdasarkan gambar 6 power output yang dihasilkan dari proses pembakaran pada tungku dengan variasi ketinggian lubang udara $10 \mathrm{~cm}, 20 \mathrm{~cm}, 30 \mathrm{~cm}, 40 \mathrm{~cm}$, dan tungku tradisional dengan ukuran bahan
Pada gambar 5 hubungan kehilangan daya dengan ketinggian lubang pemasukan udara dan ukuran bahan bakar pada tungku yang menunjukan perbanding yang lurus dengan ketinggian lubang, daya input dan daya outputnya. Semakin tinggi jarak lubang udara maka daya yang hilang akan semakin besar, hal ini disebabkan perbedaan ketinggian lubang udara menyebabkan adanya laju aliran udara yang dapat mengurangi transfer panas baik secara konveksi maupun secara radiasi, serta banyaknya daya yang terbuang kelingkungan akibat nyala api yang menyebar sehingga tidak terfokus ke alat memasak.

\section{Efisiensi ( $n$ )}

Efisiensi tungku adalah perbandingan antara energi yang digunakan pada pemanasan air (Pout) dengan energi panas yang terkandung pada bahan bakar (Pin).

Dari gambar 7 terlihat bahwa efisiensi tungku pada pemanasan air untuk masingmasing ketinggian lubang udara menunjukkan bahwa semakin tinggi jarak lubang udara

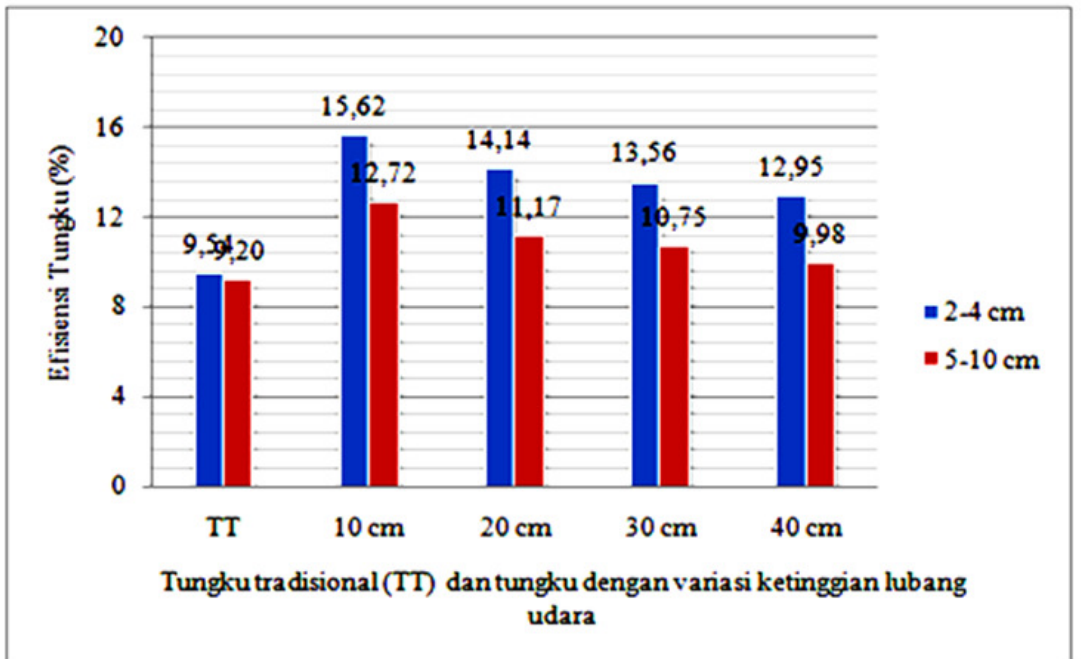

Gambar 7. Hubungan efisiensi tungku terhadap variasi lubang udara dengan ukuran panjang bahan bakar $2-4 \mathrm{~cm}$ dan $5-10 \mathrm{~cm}$

bakar 2-4 cm masing-masing adalah 0,4254 $\mathrm{kW}, 0,4621 \mathrm{~kW}, 0,5073 \mathrm{kWh}, 0,5604 \mathrm{~kW}$ dan $0,3202 \mathrm{~kW}$, sedangkan pada variasi ukuran bahan bakar 5-10 $\mathrm{cm}$ masing-masing adalah $0,4844 \mathrm{~kW}, 0,5269 \mathrm{~kW}, 0,5821 \mathrm{~kW}, 0,6363$ $\mathrm{kW}$, dan 0,3436 kW. Power output pada tungku pembakaran biomassa menunjukkan kemampuan dari tungku untuk menghasilkan energi yang nantinya akan digunakan untuk memasak/memanaskan air. semakin kecil efisiensi yang dihasilkan. Seperti yang terlihat pada penggunaan tungku dengan ketinggan lubang udara pada penggunaan bahan bakar ukuran 2-4 cm, memdapatkan nilai efisiensi sebesar $15,62 \%$ pada ketinggian lubang udara $10 \mathrm{~cm}$, dan efisiensi yang terkecil sebesar 12,95 \% pada ketinggian lubang udara $40 \mathrm{~cm}$, begitu juga dengan penggunaan tungku yang menggunakan ukuran bahan bakar $5-10 \mathrm{~cm}$, efisiensi terbesar pada ketinggian lubang 
udara $10 \mathrm{~cm}$ yaitu sebesar $12,72 \%$, dan efisiensi terkecil yang dihasilkan pada tungku dengan ketinggian lubang udara $40 \mathrm{~cm}$ sebesar 9,98 \%. Hal ini disebabkan karena nilai dari efisiensi tungku tergantung dari jumlah konsumsi bahan bakar yang digunakan pada proses pembakaran, jadi semakin tinggi jarak lubang udara dengan ukuran bahan bakar yang semakin besar akan menyebabkan konsumsi bahan bakar akan semakin besar, sehingga efisiensi tungku menjadi kecil. Selain itu juga nilai efisiensi juga tergantung dari nilai kalor bahan bakar yang digunakan.

\section{KESIMPULAN DAN SARAN Kesimpulan}

Berdasarkan hasil perhitungan dan analisa data yang telah dilakukan pada bab sebelumnya, maka dapat ditarik kesimpulan diantaranya :

1. Dari hubungan antara boiling time dengan variasi ketinggian lubang udara pada tungku dan variasi ukuran panjang bahan bakar di peroleh boiling time yang paling lambat pada ketinggian lubang udara 10 $\mathrm{cm}$ dengan ukuran bahan bakar 2-4 cm, sedangkan nilai boiling time tercepat pada tungku pembakaran dengan ketinggian lubang udara $40 \mathrm{~cm}$ dan ukuran bahan bakar $5-10 \mathrm{~cm}$. Artinya semakin tinggi jarak lubang udara, maka waktu yang dibutuhkan untuk mendidihkan air semakin cepat, dengan demikian dapat dikatakan bahwa ketinggian lubang berbanding terbalik dengan nilai boiling time yang dihasilkan.

2. Dari hubungan antara fuel consumtion rate (FCR) dengan variasi ketinggian lubang udara dan variasi ukuran bahan bakar, diperoleh kesimpulan bahwa semakin tinggi jarak lubang udara dengan bahan bakar yang besar, maka semakin besar konsumsi bahan bakar yang digunakan, artinya penggunaan bahan bakar akan semakin boros.

3. Dari hubungan antara daya pembakaran $\left(P_{\text {in }}\right)$, daya bersih $\left(P_{\text {out }}\right)$ dan daya yang hilang $\left(\mathrm{P}_{\text {loss }}\right)$ dengan variasi ketinggian lubang udara dan variasi ukuran bahan bakar diperoleh hasil bahwa semakin tinggi jarak lubang udara dengan ukuran panjang bahan bakar 5-10 cm, maka daya pembakaran dan daya bersih yang dihasilkan akan semakin besar.

4. Dari hubungan antara daya yang hilang $\left(\mathrm{P}_{\text {loss }}\right)$ dengan variasi ketinggian lubang udara dan variasi ukuran bahan bakar diperoleh hasil bahwa semakin tinggi jarak lubang udara maka daya yang hilang semakin besar, hal ini dikarenakan penggunaan diameter panci yang digunakan terlalu kecil sehingga nyala api hasil pembakaran banyak yang menyebar ke lingkungan dan tidak terfokus kealat memasak.

5. Dari hubungan antara efisiensi (n) dengan variasi ketinggian lubang udara dan variasi ukuran panjang bahan bakar dapat disimpulkan bahwa semakin tinggi jarak lubang udara dengan ukuran bahan bakar 5-10 cm, maka semakin rendah efisiensi (n) yang dihasilkan. Pada penelitin ini diperoleh efisiensi ( $\eta$ ) yang paling besar pada variasi tinggi lubang udara $10 \mathrm{~cm}$ dengan ukuran bahan bakar $2-4 \mathrm{~cm}$ yaitu $15,62 \%$, sedangkan efisiensi (n) paling rendah diperoleh dari tinggi jarak lubang udara $40 \mathrm{~cm}$ dengan ukuran bahan bakar 5-10 cm yaitu 9,98 \%. Sementra untuk tungku tradisional menghasilkan nilai efisiensi tertinggi pada ukuran bahan bakar 2-4 cm yaitu $9,72 \%$.

\section{Saran}

1. Pada penelitian selanjutnya diharapkan untuk meminimalisir kehilangan daya yang dihasilkan diantaranya dengan memperhatikan penggunaan diameter panci harus lebih besar dari diameter tungku dan ketebalan dinding tungku sehingga efisiensi yang dihasilkan akan lebih baik.

2. Untuk penelitian selanjutnya juga perlu diperhitungkan perpindahan panas baik secara konduksi, konveksi dan radiasi sehingga dihasilkan efisiensi thermal dari tungku pembakaran biomassa tersebut.

\section{DAFTAR PUSTAKA}

Anonim1, 2007, Bahan bakar dan pembakaran, Pedoman Efisiensi Energi untuk Industri di Asia pada www.energyefficiencyasia.org. diunduh pada tanggal 25 januari 2015

Barlin, Nainggolan M.P., 2012, Studi performa tungku pembakaran biomassa berbahan bakar limbah sekam padi, Prosiding Seminar Nasional Resatek, Jurusan Teknik Mesin, Fakultas Teknik, Universitas Sriwijaya, Palembang.

Budianto, A., Nurhuda, M., Nadhir , A., 2014, Uji Efisiensi Tungku Tanah Liat Berdaya Sedang, Jurusan Fisika, FMIPA, Universitas Brawijaya.

Maulana, R., 2008., Optimasi efisiensi Tungku Sekam dengan Variasi Lubang pada 
Badan Kompor, Skripsi, Institut Pertanian Bogor, Bogor.

Pranata, J., 2007, Pemanfaatan sabut dan tempurung kelapa serta cangkang sawit untuk pembuatan asap cair sebagai pengawet makanan alami, Teknik Kimia Universitas Malikussaleh Lhokseumawe, Aceh.

Suhandi, A., Rusdiana, D., Irzaman, 2013, Kajian dan terapan konsep fisika dalam desain tungku sekam, Jurusan Pendidikan Fisika, FPMIPA, Institut Pertanian Bogor.

Utami, Y., 2008, Desain dan uji unjuk kerja tungku briket biomassa , Skripsi, Fakultas Teknologi Pertanian, Institut Pertanian Bogor, Bogor.

Vidian, F., 2012, Gasifikasi tempurung kelapa menggunakan updraft gasifier pada beberapa variasi laju alir udara pembakaran, Jurusan Teknik Mesin, Fakutas Teknik, Universitas Sriwijaya, Palembang.

Widiarto, I.H., 2012, Pengaruh luas celah udara pada kompor briket batubara terhadap efisiensi waktu pendidihan air, Skripsi, Fakultas Keguruan Dan IImu Pendidikan, Universitas Jember, Jember. 